\title{
One step nucleic acid amplification (OSNA) study in Indonesia
}

\author{
Samuel J Haryono ${ }^{1 *}$, Lenny Sari ${ }^{2}$, Sony Sugiharto ${ }^{3}$, I Gusti Bagus Datasena ${ }^{4}$, \\ Raymond Mulyarahardja ${ }^{4}$, Rudianto ${ }^{5}$ \\ ${ }^{1}$ Departments of Oncology Surgery, Dharmais National Cancer Center \\ ${ }^{2}$ Departments of Anatomical Pathology, Dharmais National Cancer Center \\ ${ }^{3}$ Departments of Anatomical Pathology, Mochtar Riady Comprehensive Cancer \\ Center Hospital \\ ${ }^{4}$ Vivo Research Initiative \\ ${ }^{5}$ Scientific Marketing, PT Sysmex Indonesia
}

DOI: http://dx.doi.org/10.19106/JMedScieSup004804201625

\section{ABSTRACT}

Sentinel lymph node (SLN) is defined as the first of a few selected lymphatic nodes, into which lymphatic fluid from a primary tumor drains. Streamlined processing of SLN for detection of lymph node metastasis involves the ability to command over methodical blocks of SLN identification, surgical removal of SLN, and SLN analysis. One Step Nucleic Acid Amplification (OSNA) method, which relies on CK19 mRNA expression to detect intra-operative lymph node metastases in breast cancer cases, has emerged as plausible alternative to the current histopathological gold standard. This research involved sixty selected axillary SLN from thirty breast cancer patients. SLN were directly bi-halved after collection using customized lymph node cutting device (Sysmex), or scalpel. The first halves were subjected to histopathological examination and were stored in specimen containers containing fresh formaldehyde prior to processing. The adjacent halves were weighed to comply with the required mass by OSNA detection in the range of $50-600 \mathrm{mg}$ and wrapped in clean foils for storage in $-80^{\circ} \mathrm{C}$ prior to OSNA analysis. 60 SLNs had same diagnosis using both methods. 25 SLNs were negative and 25 SLNs were positive using both methods. 3 SLNs were positive on OSNA but negative on histology. Other 7 SLNs were negative on OSNA but positive on histology, and these 1 nodes contained only micrometastasis lesion. These results suggested that OSNA is a useful for detecting SLNs metastasis, but a copy number of CK19 might be an indepedent factor in prediction and prognosis of breast cancer.

Keyword: OSNA, Sentinel Nodes, Breast Cancer, CK19

$\overline{\text { Corresponding author: samuelharyono@yahoo.com }}$ 